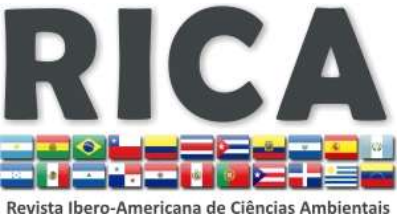

Journals Homepage:

www.sustenere.co/journals

\section{EUTROFIZAÇÃO: ASPECTOS CONCEITUAIS, USOS DA ÁGUA E DIRETRIZES PARA A GESTÃO AMBIENTAL}

\section{RESUMO}

Nessa revisão foram abordados aspectos conceituais relacionando o crescimento populacional humano aos usos múltiplos da água e à eutrofização. Foram apontados os problemas associados ao descarte de nutrientes na água e as consequências da eutrofização. As bases conceituais envolvendo os aspectos ecológicos e de modelagem matemática também foram considerados. Por último, as várias diretrizes para a gestão ambiental envolvendo a eutrofização foram discutidas tanto no âmbito federal quanto no âmbito estadual, assim como as ferramentas de gestão envolvidas na esfera local e específica quanto na delimitação da bacia hidrográfica. Com base nos conceitos e discussões sobre a eutrofização apresentados nessa revisão, é notório que o enriquecimento de nitrogênio e fósforo é um dos principais problemas não somente no Brasil, mas também no mundo. Apesar da existência de diversas formas de tecnologias para tratar esse problema, a prevenção ainda é uma das melhores alternativas para evitar a eutrofização.

PALAVRAS-CHAVES: Fósforo; Legislação; Nitrogênio; Poluição.

\section{EUTROPHICATION: CONCEPTUAL ASPECTS, MATHEMATICAL MODELING AND ENVIRONMENTAL MANAGEMENT}

\section{ABSTRACT}

In this review was addressed conceptual issues related to human population growth, the water multiple uses of eutrophication. We pointed out several problems associated to the input of nutrients the aquatic ecosystem and, the consequences of eutrophication. The conceptual bases involving ecological aspects and mathematical modeling were also considered in the discussion of this review. Finally, the directions for the environmental management involving within eutrophication have been discussed both in the federal and state levels, as well as, the management tools involved in the local and specific areas considering the delimitation of the watershed. Based on the concepts and discussions about eutrophication presented in this review, it is clear that the enrichment of nitrogen and phosphorus is a major problem in Brazil and also worldwide. Despite the existence of various types of technology to address this problem, the prevention is the best alternative to control eutrophication.

KEYWORDS: Legislation; Nitrogen; Phosphorous; Pollution.
Revista Ibero-Americana de

Ciências Ambientais, Aquidabã, v.6, n.1, Dez 2014, Jan, Fev, Mar, Abr, Mai 2015.

ISSN 2179-6858

\section{SECTION: Articles}

TOPIC: Físico-Química Ambiental

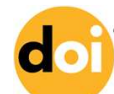

DOI: 10.6008/SPC2179-6858.2015.001.0006

Camila dos Santos Ferreira

Universidade Federal de São Carlos, Brasil http://lattes.cnpq.br/2701967377951518

$$
\text { camila csf@yahoo.com.br }
$$

Marcela Bianchessi da Cunha-Santino Universidade Federal de São Carlos, Brasil http://lattes.cnpq.br/2356641063223397 cunha santino@ufscar.br

Irineu Bianchini Júnior

Universidade Federal de São Carlos, Brasil http://lattes.cnpq.br/0659731944736389 irineu@power.ufscar.br

Received: 14/07/2014

Approved: 14/10/2015

Reviewed anonymously in the process of blind peer.

\section{Referencing this:}

FERREIRA, C. S.; CUNHA-SANTINO, M. B.; BIANCHINI JUNIOR, I.. Eutrofização: aspectos conceituais, usos da água e diretrizes para a gestão ambiental. Revista Ibero-Americana de Ciências Ambientais, Aquidabã v.6, n.1, p.65-77, 2015. DOI: http://dx.doi.org/10.6008/SPC2179- 


\section{INTRODUÇÃO}

Os corpos de água doce podem ser considerados como um recurso alicerce para o desenvolvimento das populações humanas, uma vez que, para a progressão da vida é necessário o uso metabólico da água. O crescimento populacional mundial vem se intensificando desde a década de 50 do século XX, apresentando uma taxa de crescimento de ca. 1,2\% ao ano (UNITED NATIONS, 2004). No Brasil considerando o período de 2000-2010, a taxa de crescimento foi $1,17 \%$ ao ano (IBGE, 2010). Novaes (2000) aponta que no período de 1960 a 1990 a população urbana brasileira cresceu 3,9 vezes enquanto que a rural caiu $14 \%$. Uma das expressões do crescimento dos centros urbanos pode ser evidenciada no aumento da poluição dos recursos hídricos (ex. rios, lagos e reservatórios). Ao se considerar a utilização dos recursos hídricos emerge o conceito de usos da água, que se refere aos múltiplos fins que se destinam os recursos hídricos (ABNT, 1993). Uma revisão sobre usos da água realizada por Gleick (2003) mostra várias distinções entre os conceitos de: necessidade de água: que se refere à mínima quantidade de água necessária para satisfazer a uma finalidade específica; demanda por água: refere-se a um conceito econômico frequentemente usado para descrever a quantidade de água requerida ou exigida por um utilizador (ex. indústria) e retirada de água: geralmente refere-se à água removida a partir de uma fonte e sua utilização para as necessidades humanas. Parte dessa água pode retornar para a fonte de origem com possíveis mudanças na quantidade e na qualidade, e outra parte pode ser utilizada (i.e consumida). Nesse sentido, os usos dos recursos hídricos ocorrem de duas formas: consuntivos ou não consuntivos. Os usos consuntivos são aqueles que retiram água de sua fonte natural diminuindo suas disponibilidades, quantitativa ou qualitativa, espacial e temporalmente (SETTI et al., 2001). Os usos não consuntivos são aqueles em que toda a água captada retorna ao local de origem (SETTI et al., 2001).

No geral, é possível categorizar o uso da água em três grandes setores: agrícola, industrial e doméstico. Considerando o panorama mundial e o brasileiro, tem-se a seguinte distribuição em ordem crescente de uso da água: agricultura, industria e doméstico. As maiores demandas de água referem-se ao uso agrícola, sendo que a principal atividade consumidora de água é a irrigação. Na pecuária, a água é basicamente utilizada na dessedentação de animais. O uso doméstico abrange descargas de bacias sanitárias, higienização pessoal, limpeza, rega de jardins e quintais, lavagem de roupa e consumo humano. Em relação ao uso da água industrial citam-se as seguintes atividades: matéria-prima, processos industriais, resfriamento e instalações de refeitórios e sanitários (COSTA, 2007).

Pode-se discutir, ainda, a utilização da água do ponto de vista dos serviços dos ecossitemas. Esse conceito refere-se aos serviços prestados pelo ambiente natural que beneficiam as pessoas e contribuem para o bem-estar humano (DEFRA, 2007). O programa de trabalho internacional denomindo Avaliação Ecossistêmica do Milênio (Millenium Ecossystem Assessment) categorizou os serviços dos ecossistemas em quatro grandes grupos: serviços de provisão: uso da água para uso consuntivo e não consuntivo e utilização de organismos aquáticos para alimentação e usos medicinais serviços reguladores: Manutenção da qualidade da água 
(diluição e autodepuração) e Controle de cheias e de erosão (interação água-terra) serviços culturais: turismo e recreação e serviços de suporte: processos ecológicos relacionados a ciclagem de nutrientes e de carbono, produção primária e relações predador/presa (POSTEL \& CARPENTER, 1997; MILLENNIUM ECOSYSTEM ASSESSMENT, 2005).

A água fornece uma série de serviços, e com sua utilização as pressões antrópicas sobre o recurso hídrico geram mudanças qualitativas e quantitativas nos ecossistemas aquáticos. No Brasil, a eutrofização dos corpos d'água representa um dos grandes problemas de qualidade da água (ANA, 2012). No cenário mundial, este também é o principal problema relacionado tanto com as águas continentais quanto as marinhas (RAST et al., 1989; SMITH \& SCHINDLER, 2009; UNEP, 2001), sendo que as principais atividades responsáveis por esse problemas são excesso de fertilizantes utilizados em práticas agrícolas, pecuária (dejetos animais) e despejos de esgotos domésticos (dejetos humanos e detergentes) e industriais sem tratamento prévio em ambientes lóticos e águas pluviais de regiões com intensa poluição atmosférica (SIQUEIRA \& OLIVEIRAFILHO, 2005).

\section{METODOLOGIA}

Este revisão consistiu em um estudo exploratório da literatura que visou identificar o estado da arte relacionado aos aspectos relevantes da eutrofização considerando as diretrizes de gestão ambiental e os usos da água. Para a realização da pesquisa foram utilizadas as bases de dados Scopus e Science Direct (string: eutrophication), banco de teses e dissertações, sites de órgãos reguladores, livros e leis. O recorte temporal abrangeu o período ente 1950 a 2012.

\section{RESULTADOS}

\section{Bases Conceituais da Eutrofização}

Define-se a eutrofização como o processo de enriquecimento das águas com nutrientes, principalmente fósforo e nitrogênio (RAST et al., 1989). Os nutrientes subsidiam o crescimento dos produtores primários (ex. fitoplâncton e macrófitas aquáticas) e na situação quando o nitrogênio e o fósforo não se constituem em fatores limitantes, ocorre o crescimento excessivo dos vegetais (RAST et al., 1989). Várias são as consequências desse crescimento acentuado nos ambientes aquáticos, dentre as quais se citam: anoxia, que tem como consequência a morte de organismos com respiração aeróbia; crescimento excessivo de plantas aquáticas, i.e. floração de algas, cianobactérias e macrófitas aquáticas; efeitos sobre a saúde humana pela produção de cianotoxinas; concentrações elevadas de matéria orgânica resultantes da morte da biomassa de produtores primários; restrição à pesca e atividades recreativas, devido ao excesso de biomassa de macrófitas aquáticas; mudança na biodiversidade aquática e alteração na composição de espécies; aumento no custo para o tratamento de água caso o sistema aquático seja utilizado 
para abastecimento; redução na navegação e na capacidade de transporte; diminuição da transparência da água com decréscimo da penetração de radiação; e mudanças amplas na variação de pH (TUNDISI \& TUNDISI-MATSUMURA, 2002; XAVIER et al., 2005; HILTON et al., 2006; SMITH \& SCHINDLER, 2009; SHAW et al., 2003; ANA, 2012). A eutrofização resulta em efeitos deletérios sobre a estabilidade biológica de um ambiente lêntico, mostrando impactos negativos do ponto de vista ecológico, da saúde, social e econômico (RAST et al., 1989).

Atualmente no Brasil existe uma vasta literatura sobre eutrofização e suas consequências; dentre as quais é possível citar várias revisões sobre floração de cianobactérias (SIQUEIRA \& OLIVEIRA-FILHO, 2005; BRANDÃO \& DOMINGOS, 2006; MOSCHINI-CARLOS \& NISHIMURA, 2011), eutrofização em lagos e reservatório (TUNDISI, 2003; TUNDISI et al., 2002; MEDIONDO, 2008), manejo de macrófitas aquáticas (THOMAS \& BINI, 1998; POMPÊO, 2008; MOURA et al., 2002) gestão integrada de mananciais de abastecimento eutrofizados (ANDREOLI \& CARNEIRO, 2005), ecohidrobiologia e manejo sustentável (MORAES, 2009). Em revisões internacionais, como a elaborada por Smil (2000), foram discutidas as interferências humanas e os fluxos naturais do fósforo nos ecossistemas aquáticos. Yang et al. (2008) revisaram os mecanismos e o monitoramento de águas eutrofizadas. Mateo-Sagasta; Burke (2010) publicaram um relatório intitulado "Agricultura e interações como a qualidade da água: uma visão geral", discutindo sobre a agricultura e a qualidade da água, e indicando que o excesso de nutrientes causa hipóxia e aumento da biomassa algas, além dos nitratos percolarem até as águas subterrâneas.

Com base na origem, pode-se classificar a eutrofização em dois tipos: natural e acelerada ou cultural. A eutrofização natural resulta da fertilização decorrente do envelhecimento do corpo de água, na escala geológica de tempo (HILTON et al., 2006). Assim, por esse modelo, inicialmente um ambiente aquático apresenta águas oligotróficas (baixas concentrações de nutrientes), passa pelo estado mesotrófico (concentrações intermediárias de nutrientes) e ao envelhecer torna-se eutrófico. A eutrofização acelerada ou cultural refere-se ao rápido aumento do estado trófico de um corpo de água devido às ações antrópicas, tais como a urbanização e a industrialização (KHAN \& ANSARI, 2005; SHAW et al., 2003).

Considerando a eutrofização, as fontes de nutrientes podem ser classificadas em: difusas e pontuais. As fontes difusas (também chamadas de não pontuais) originam-se de múltiplos pontos de descarga, abrangendo grandes áreas e geralmente associadas ao uso da terra (p. ex. os escoamentos superficiais urbanos e agrícolas). As fontes pontuais resultam da descarga de nutrientes em locais específicos que podem ser facilmente identificados, como por exemplo, esgotos domésticos e industriais (BRUSSEAU \& TICK, 2006).

Rockström et al. (2009) propuseram a abordagem do espaço operacional seguro para a humanidade. Essa abordagem identifica e quantifica os limites planetários que não devem ser transgredidos pelas ações antrópicas que causam mudanças ambientais. Os autores apontam que as interferências nos ciclos do nitrogênio já ultrapassaram o espaço seguro. A agricultura moderna, principalmente a fabricação de adubo para a produção de alimentos e o cultivo de leguminosas, é uma das principais causas do incremento de nitrogênio e fósforo em escala 
planetária, e está perturbando significativamente os ciclos globais destes dois elementos. Um estudo sobre as concentrações de nitrato na foz de rios mostrou que os rios europeus foram os que apresentaram as cargas mais elevadas de nitrato e que esse é transportado para o ambiente marinho (UNEP, 2008). Comparando os dados de duas décadas passadas, as cargas de nitrato dos rios norte-americanos e europeus permaneceram estáveis, enquanto que os rios da hidrográficas na região centro-sul e sudeste da Ásia registraram elevações na concentração de nitratos (UNEP, 2008).

\section{Enriquecimento de nutrientes: modelagem e respostas funcionais}

Três relações empíricas têm sido utilizadas para simular a cinética de absorção de nutrientes pelas algas: o modelo de Michaelis-Menten, o modelo de Monod e o modelo de Droop Borchardt (1996), na abordagem, esses modelos são semelhantes. O modelo de MichaelisMenten enfatiza cinética de absorção de nutrientes Dugdale (1967), o de Monod relaciona o coeficiente de crescimento em função da concentração de nutrientes do ambiente Monod (1950), enquanto que o modelo Droop considera a concentração intracelular do nutriente limitante (DROOP, 1968). Esses modelos postulam que os coeficientes de crescimento atingem um valor máximo a uma determinada concentração. A equação de Monod (Equação 1) tem sido aplicada em vários estudos e modelos matemáticos para investigar a relação de produção de algas e as concentrações externas de nutrientes (ex. BOWIE et al., 1985).

$$
\mu=\mu_{\text {MAX }} \times \frac{[S]}{K_{S}+[S]}(1),
$$

Em que $\mu$ é o coeficiente específico de crescimento (dia-1); $\mu_{\operatorname{MAx}}$ é o coeficiente específico máximo de crescimento ( dia $^{-1}$ ); $\mathrm{K}_{\mathrm{s}}$ constante de meia saturação em relação à concentração do nutriente limitante $\left(\mu \mathrm{gL}^{-1}\right)$ e $S$ se refere à concentração externa do nutriente $\left(\mu \mathrm{gL}^{-1}\right)$ (RIER \& STEVENSON, 2006).

Nos ambientes aquáticos, vários experimentos confirmaram que o crescimento do perifíton aumenta ao longo de gradientes de nutrientes (WALTON et al.,1995; STEVENSON, 1996; STEVENSON et al., 2006). Análises de correlação entre as concentrações de nutrientes, biomassa e produtividade de algas também indicaram que o enriquecimento de nutrientes incrementa a produção de biomassa algal (DODDS et al., 2002). Comparando dados de produção de algas e biomassa foi verificada correlação positiva entre a produção primária e biomassa de algas em ambientes lóticos, embora apenas $24 \%$ da variação tenham sido explicadas (DODDS, 2006). As observações de campo são consistentes com as manipulações experimentais de enriquecimento de nutrientes e produção de algas, e conforme verificado para algas, a produção de macrófitas aquáticas também é estimulada pelo enriquecimento de nutrientes (GUCKER et al., 2006; PISTORI et al., 2010).

É geralmente aceito que uma maior produção leve a uma maior respiração. A produção e a respiração por algas estão correlacionadas (DODDS, 2006). Do mesmo modo, o enriquecimento 
de nutrientes aumenta a produção de bactérias e fungos, que por sua vez, aumentam a respiração aeróbia (LEMOS et al., 2007). Assim, a respiração total em ambientes aquáticos enriquecidos é maior do que a produção. Em córregos enriquecidos com nutrientes, as relações elevadas entre respiração e produção (R/P) levam a valores elevados de demanda bioquímica de oxigênio (DBO) nas águas a jusante. Assim, o enriquecimento de nutrientes, conduz geralmente à elevação da produção primária bruta e da respiração de toda a comunidade, diminuindo as concentrações de oxigênio dissolvido (GUCKER et al., 2006). Por exemplo, estudos de carga de nutrientes no fitoplâncton, no bacterioplâncton e na respiração indicaram que incrementos na carga de nutrientes estimularam as atividades fotossintéticas e heterotróficas (MALLIN et al., 2004). As adições de nitrogênio aumentaram a produção de clorofila-a e significativamente a DBO. Por sua vez, as adições de fósforo estimularam a abundância bacteriana, o teor de ATP e a DBO na maioria das ocasiões. Desse modo, devido às adições de nitrogênio e fósforo, a ocorrência de hipóxia é um processo decorrente (MALLIN et al., 2006).

Normalmente o carbono não se constitui em elemento limitante em ambientes aquáticos. Contudo, em ambientes estratificados e com pouca circulação o $\mathrm{CO}_{2}$ dissolvido pode não ser suficiente para a manutenção da produção primária (WETZEL, 2001). Em ambientes com entradas relativamente baixas de COD (ex. córregos de baixa ordem), as bactérias são limitadas por carbono (SUBERKROPP \& CHAUVET, 1995). Aumentos na produção primária, devido ao enriquecimento de nutrientes incrementam as concentrações de COD e o acoplamento do perifíton e bactérias, já que as bactérias dependem mais de fontes de carbono orgânico produzidas por algas e por outras plantas (MALLIN et al., 2004).

A fixação de nitrogênio por algas e bactérias pode ser afetada por adições de nutrientes e consequente mudanças na relação N:P (SMITH et al., 1999). Esse processo é favorecido pelo movimento lento da água, por temperaturas elevadas, pelas concentrações baixas de compostos nitrogenados inorgânicos e por concentrações altas de compostos nitrogenados orgânicos (ALLAN, 1995). A fixação de nitrogênio pode fornecer quantidades substanciais desse elemento à ambientes oligotróficos (GRIMM \& PETRONE, 1997). Estudos realizados em lagos indicaram que reduções na razão N:P geralmente levam a aumentos nas taxas de fixação de $\mathrm{N}$ por cianobactérias (HENDZEL et al., 1994). Verificou-se ainda que a biomassa responsável pela fixação do $\mathrm{N}_{2}$ foi positivamente correlacionada com a temperatura e luz, e negativamente com nitrogênio inorgânico dissolvido (GRIMM \& PETRONE, 1997).

Em vista do aumento da produção primária devido aos enriquecimentos de nitrogênio e fósforo, é normalmente esperado que a produção e biomassa dos consumidores aumentem (GLIBERT, 1998). A produção secundária responde claramente ao enriquecimento e a resposta pode ser mais evidente nos ambientes oligotróficos que nos eutróficos (ROSEMOND et al., 1993). Os peixes, especialmente os herbívoros, podem, obviamente, beneficiar-se do aumento da biomassa dos produtores primários. Vertebrados carnívoros ou onívoros também podem prosperar a partir do aumento da biomassa dos consumidores primários (ex. DEEGAN \& PETERSON, 1992). 
A resposta inicial a um enriquecimento de nutrientes em um córrego em região de floresta foi o aumento da biomassa de algas, que em seguida foram consumidas devido ao grande aumento na abundância de pastadores (ELWOOD et al., 1981). O enriquecimento contínuo de rios limitados por fósforo levou a aumentos substanciais dos produtores secundários; a biomassa de invertebrados bentônicos aumentou de 2 a 7 vezes e a de peixes de 1,4 a 2 vezes. Em um rio enriquecido com carbono, devido à elevada biomassa bacteriana, a massa de macroinvertebrados, que são consumidores de bactérias (FULLER et al.,1986), aumentou 4,5 vezes e a de peixe 6,3 vezes (WARREN et al., 1964). Em outro estudo, o enriquecimento não causou um aumento geral na densidade de macroinvertebrados ou biomassa, mas alterou a composição da comunidade (SABATER et al., 2005). Nesse contexto, as alterações e perdas da biodiversidade são usualmente relatadas em ambientes eutrofizados (DODDS et al., 2009).

A decomposição é também afetada por vários fatores ambientais, (ex. velocidade de corrente, alimentação por detritívoros, sedimentação, temperatura, $\mathrm{pH}$, tamanho de partícula, composição química do detrito, potencial de oxi-redução, eutrofização). No que se refere à simulação dos efeitos da eutrofização sobre a decomposição, as mesmas relações empíricas utilizadas para a produção primária são frequentemente empregadas (ex. Monod). Os coeficientes de decomposição são também fortemente afetados pela produtividade de fungos e bactérias e suas contribuições relativas à biomassa microbiana total (HIEBER \& GESSNER, 2002). O enriquecimento de nutrientes geralmente aumenta a produtividade e a biomassa de bactérias e fungos, mas não altera os papéis de cada comunidade (GULIS \& SUBERKROPP, 2003).

Os incrementos de nutrientes aumentam os coeficientes de perda de massa, a respiração microbiana, a biomassa fúngica e bacteriana, e a taxa de esporulação de hyphomycetes aquáticos associados com a decomposição de folhas (GULIS \& SUBERKROPP, 2003). Comparações entre um local de referência no rio Ave (Portugal) e dois locais localizados à jusante e poluídos com concentrações elevadas de nutrientes indicaram que a produção bacteriana foi maior nos locais poluídos, enquanto que a maior produção de biomassa de fungos correspondeu à decomposição mais rápida de folhas (PASCOAL \& CÁSSIO, 2004). Outros estudos também mostraram a contribuição de fungos e bactérias para a decomposição de serapilheira e o incremento da atividade microbiana pelos nutrientes (SUBERKROPP \& CHAUVET, 1995; WEYERS \& SUBERKROPP, 1996; ROYER \& MINSHALL, 2001; GULIS \& SUBERKROPP, 2003).

\section{Gestão de Bacias Hidrográficas}

Para adotar a bacia hidrográfica como uma unidade de planejamento deve-se primeiramente identificar as políticas públicas adequadas, os objetivos, os planos, as prioridades no uso integrado do solo e da água tendo em vista a conservação ambiental (NASCIMENTO \& VILLAÇA, 2008). Em um segundo momento, deve-se desenvolver a capacidade de gerir os conflitos, identificar potencialidades, fragilidades e visualizar cenários para o longo prazo (NASCIMENTO \& VILLAÇA, 2008). A ausência ou a resistência de partes interessadas (ex. 
sociais, políticas, econômicas e ambientais) em considerar a gestão de uma bacia hidrográfica de maneira sistêmica representa prejuízos ambientais e sociais. Nesse sentido, a qualidade da água dos recursos hídricos é afetada pelas ações degradativas causadas pelo homem que tem a preocupação apenas com a qualidade da água utilizada e um total descompromisso com o descarte adequado de seus efluentes líquidos (RIO et al., 2002).

Tundisi (2003) aponta que para um planejamento ambiental integrado e eficaz em uma bacia hidrográfica é necessário considerar: a visão das bacias hidrográficas como uma unidade de gerenciamento, de planejamento e de ação; a água como um fator econômico; um plano articulado, tanto com projetos sociais quanto econômicos; a participação da comunidade, dos usuários e de organizações públicas e privadas; a educação sanitária e ambiental da comunidade; o treinamento técnico e administrativo; o monitoramento ambiental permanente, com a participação da comunidade; a integração entre engenharia, operação e gerenciamento de ecossistemas aquáticos; a constante prospecção e avaliação de impactos e tendências e implantação de sistemas de suporte à decisão.

Em áreas urbanas, as bacias hidrográficas são influenciadas diretamente pelo grau de urbanização em que, geralmente, os grandes municípios sofrem com as condições do abastecimento de água e de tratamento de esgoto. Diante desse cenário, um dos principais desafios para os gestores é a conservação dos mananciais, nascentes e água subterrânea considerando o uso e ocupação do solo (NASCIMENTO \& VILLAÇA, 2008). O uso e a ocupação desordenados do solo geram vários problemas ambientais que comprometem a qualidade dos recursos hídricos, sendo os principais: o aumento de erosões e perdas de solos; o assoreamento de rios, represas, lagos e açudes; a diminuição da qualidade da água; o desmatamento; a perda de biodiversidade; o aumento da entrada de nutrientes nos ambientes aquáticos; eutrofização; a proliferação de algas prejudiciais à saúde humana e o aumento da turbidez.

$\mathrm{Na}$ mitigação ou neutralização da eutrofização, os princípios da ecologia da paisagem devem ser levados em consideração. Nesse caso, devem ser destacadas duas abordagens distintas: uma geográfica, que tem como enfoque a gestão territorial e estuda a influência das atividades humanas sobre a paisagem, e a outra ecológica, que enfatiza a relação entre o homem, a natureza e o contexto espacial em termos de conservação biológica (METZGER, 2001). A ecologia da paisagem proporciona uma 'solução espacial' levando em consideração a capacidade de suporte do ambiente e a modelagem do arranjo espacial para que a sociedade possa viver em harmonia com o ambiente sem exercer influências negativas (MOSCHINI, 2005). Dessa forma, é possível constatar que ainda existe dificuldade em estabelecer os modelos espaciais no planejamento de paisagens sustentáveis, pois ainda é necessário avaliar o histórico dos processos de transformações do ambiente, já que perturbações ocorridas no passado podem exercer efeitos de longo prazo no ambiente (MOSCHINI, 2005). 


\section{Medidas de Prevenção}

Diante da revisão, é notório que o enriquecimento de nitrogênio e fósforo é um dos principais problemas não somente no Brasil, mas também no mundo. Apesar da existência de diversas formas de tecnologias para tratar esse problema, a prevenção, ainda, é uma das melhores alternativas para evitar a eutrofização. Dentre as ações de prevenção citam-se três tipos de medidas.

Em relação à atenuação da autofertilização: Inativação do $P$ : $P$ se liga quimicamente com íons metálicos como $\mathrm{Al}$ ou $\mathrm{Fe}$ (sulfato de alumínio ou cloreto de Fe) resultando num complexo metálico que precipita e forma uma camada inerte não deixando haver difusão e pode ser removida mecanicamente (UNEP, 2001); Método RIPLOX (Ripl, 1976): reduz a carga interna de P pela oxidação da camada da superfície do sedimento que ocasiona a precipitação do $\mathrm{P}$ em complexos metálicos. Adicionando nitrato de cálcio $\left[\mathrm{Ca}\left(\mathrm{NO}_{3}\right)_{2}\right]$ e adicionando percloreto de $\mathrm{Fe}$ $\left[\mathrm{FeCl}_{3}\right]$, injeta-se agentes oxidantes e $\mathrm{Fe}$ no ambiente, o $\mathrm{P}$ adsorve ao $\mathrm{Fe}$ e complexa. $\mathrm{O} \mathrm{pH}$ é estabilizado com hidróxido de cálcio que em $\mathrm{pH}$ adequado as bactérias desnitrificantes transformam o $\mathrm{NO}_{3}^{-}$em $\mathrm{N}_{2}$; Dragagem e remoção (UNEP, 2001): devido às razões econômicas a dragagem só é possível para ambientes pequenos e rasos; Remoção da água do hipolímnio (UNEP, 2001); e Aeração do hipolímnio (UNEP, 2001; SONDERGAARD, 2007).

Em relação à diminuição da produção primária, i.e. biomanipulação (BERNARDI \& GIUSSANI, 1995): termo cunhado em meados de 1970 e refere à manipulação da biota para tornar o corpo d'água mais agradável para os humanos. A biomanipulação é efetivada pela redução dos peixes zooplanctófagos tanto pela adição de peixes piscívoros ou mesmo removendo estes manualmente por rede de arraste. Em teoria, se o número de peixes é reduzido de modo que a pressão sobre o zooplâncton diminui a pastagem sobre as algas cresce. Dessa maneira, a probabilidade de florescimento de algas diminui e a transparência da água aumenta, i.e. controle top-down (KOPP et al., 2009). Em relação ao tratamento de águas residuais ou escoamento superficial vindo de fontes difusas: Áreas alagadas construídas (Carvalho et al., 2012) e Tratamento convencional de águas residuárias, com ênfase no tratamento terciário que visa, também, a remoção de nutrientes (DAVIS \& CORNWELL, 2006).

\section{CONCLUSÕES}

Diante das discussões apresentadas nesse artigo de revisão concluímos que atualmente a eutrofização é o principal problema relacionado à perda de qualidade das águas continentais. Assim, a sociedade civil, órgãos públicos e privados devem conscientizar-se da realidade existente e desenvolver novas tecnologias, políticas públicas, programas de educação ambiental entre outros para que esse quadro seja revertido. 


\section{REFERÊNCIAS}

ASSOCIAÇÃO BRASILEIRA DE NORMAS TÉCNICAS (ABNT). NBR 9896: Glossário de Poluição das Águas. Rio de Janeiro: ABNT, 1993.

ALLAN, J. D.. Stream Ecology: structure and function of running water. London: Chapman \& Hall, 1995.

ANDREOLI, C. V.; CARNEIRO, C.. gestão integrada de mananciais de abastecimento eutrofizados. Curitiba: SANEPAR, 2005.

BERNARDI, R.; GIUSSANI, M.. Guideline of lakeand management: biomanipulation. New York: ILEC and UNEP, 1995.

BORCHARDT. M. A. A.. Ecology: Freshwater Benthic Ecosystems. San Diego: Academic Press, 1996.

BOWIE, G. L. et al. Rates, constants and kinetics formulations in surface water quality modeling. Antenas: EPA, 1985.

BRANDÃO, L. H.; DOMINGOS, P... Fatores ambientais para a floração de cianobactérias tóxicas. Saúde \& Ambiente em Revista, v.1, n.2, p.40-50, 2006.

BRUSSEAU, M. L.; TICK, G. R.. Environmental and pollution science. San Diego: Elsevier, 2006.

CARVALHO, S. T. et al. Avaliação do Uso de Áreas Construídas de Superfície Alagada Livre (SAL) para Tratamento de Efluentes Superficiais de Pátios de Compostagem da Indústria de Celulose. Revista Brasileira de Recursos Hídricos, v.17, n.2, p.131-142, 2012.

COSTA, R. H. P. G.. Reúso da água: conceitos, teorias e práticas. São Paulo: Blucherm, 2007.

DAVIS, M.; CORNWELL, D.. Introduction to Environmental Engineering. McGraw-Hill Science, 2006.

DEEGAN, L. A.; PETERSON, B. J.. Whole-River Fertilization Stimulates Fish Production in an Arctic Tundra River. Canadian Journal of Fisheries and Aquatic Sciences, v.49, n.9, p.1890-1901, 1992.

DOI: http://10.1139/f92-209

DEPARTMENT OF ENVIRONMENT FOOD AND RURAL AFFAIRS - DEFRA. An introductory guide to valuing ecosystem services. London: Department for Environment, Food and Rural Affairs Nobel House, 2007.

DODDS, W. K. Eutrophication and trophic state in rivers and streams. Limnology Oceanography, v.51, n.1, p.671-680, 2006. DOI: http://dx.doi.org/10.4319/lo.2006.51.1 part 2.0671

DODDS, W. K. et al. Eutrophication of U.S. freshwaters: analysis of potential economic damages.

Environmental Science \& Technology, v.43, n.1, p.12-19, 2009. DOI: http://dx.doi.org/10.1021/es801217q

DODDS, W. K.; SMITH, V.H.; LOHMAN, K.. Nitrogen and phosphorus relationships to benthic algal biomass in temperate streams. Canadian Journal of Fisheries and Aquatic Sciences, v.59, n.5, p.865-874, 2002. DOI: http://dx.doi.org/10.1139/F02-063

DROOP, M. R.. Vitamin B12 and marine ecology, IV. Journal of the Marine Biological Association of the United Kingdom, v. 48, n.3, p.689-733, 1968. DOI: http://dx.doi.org/10.1017/S0025315400019238

DUGDALE, R. C.. Nutrient limitation in the sea: dynamics, identification, and significance. Limnology Oceanography, v.12, n.4, p.685-695, 1967. DOI: http://10.4319/lo.1967.12.4.0685

ELWOOD, J. W. et al. The limiting role of phosphorus in a woodland stream ecosystem: Effects of $P$ enrichment on leaf decomposition and primary producers. Ecology, v.62, n.1, p.146-158, 1981. DOI: http://dx.doi.org/10.2307/1936678

FULLER, R. L.; ROELOFS, J. A.; FRY, T. J.. The importance of algae to stream invertebrates. Journal of the North American Benthological Society, v.5, n.4, p.290-296, 1986.

GLEICK, P. H.. Water use. Annual Review of Environmental Resource, v.28, p.275-314, 2003. DOI: http://dx.doi.org/10.1146/annurev.energy.28.040202.122849 
GLIBERT, P. M.. Interactions of top-down and bottom-up control in planktonic nitrogen cycling. Hydrobiologia, v.363, n.1-3, p.1-12, 1998. DOI: http://dx.doi.org/10.1023\%2FA\%3A1003125805822

GRIMM N. B.; PETRONE, K. C.. Nitrogen fixation in a desert stream ecosystem. Biogeochemistry, v.37, n.1, p.33-61, 1997. DOI: http://dx.doi.org/10.1023/A:1005798410819

GUCKER, B., BRAUNS, M.; PUSCH, M. T.. Effects of wastewater treatment plant discharge on ecosystem structure and function of lowland streams. Journal of the North American Benthological Society, v.25, n.2, p.313-329, 2006.

GULIS, V.; SUBERKROPP, K.. Effect of inorganic nutrients on relative contributions of fungi and bacteria to carbon flow from submerged decomposing leaf litter. Microbial Ecology, v.45, n.1, p.11-19, 2003.

GULIS, V.; SUBERKROPP, K.. Leaf litter decomposition and microbial activity in nutrient-enriched and unaltered reaches of a headwater stream. Freshwater Biology, v.48, n.1, p 123-134, 2003.

GULIS, V.; SUBERKROPP, K.. Interactions between stream fungi and bacteria associated with decomposing leaf litter at different levels of nutrient availability. Aquatic Microbial Ecology, v.30, p.149157, 2003.

HENDZEL, L. L.; HECKY, R. E.; FINDLAY, D. L.. Recent changes of N2-fixation in lake 227 in response to reduction of the N: $P$ loading ratio. Canadian Journal of Fisheries and Aquatic Sciences, v.51, n.10, p.2247-2253, 1994.

HIEBER, M.; GESSNER, M. O.. Contribution of stream detritivores, fungi, and bacteria to leaf breakdown based on biomass estimates. Ecology, v.83, n.4, p.1026-1038, 2002.

HILTON, J. et al. How green is my river? A new paradigm of eutrophication in rivers. Science of the Total Environment, v.365, n.1-3, p.66-83, 2006. DOI: http://dx.doi.org/10.1016/j.scitotenv.2006.02.055

\section{INSTITUTO BRASILEIRO DE GEOGRAFIA E ESTATÍSTICA (IBGE). 2010. Censo Demográfico 2000-} 2010.

KHAN, F. A.; ANSARI, A. A.. Eutrophication: An Ecological Vision. The Botanical Review, v.71, n.4, p.449482, 2005.

KOPP, D. et al. Stability of Benthic Coral Reef Communities: Top-down herbivory control versus bottom-up eutrophication. Guadeloupe: Gulf and Caribbean Fisheries Institute, 2009.

LEMOS, R. M. A.; BIANCHINI JR. I.; CUNHA-SANTINO, M. B.. Effect of nitrogen availability on the oxygen consumption during mineralization of Scirpus cubensis from Infernão Lagoon (São Paulo-Brazil). Biological Sciences, v.29, n.2, p.177-183, 2007.

MALLIN, M. A. et al. Photosynthetic and heterotrophic impacts of nutrient loading to blackwater streams. Ecological Applications, v.14, n.3, p.823-838, 2004. DOl: http://dx.doi.org/10.1890/02-5217

MALLIN, M. A. et al. Factors contributing to hypoxia in rivers, lakes and streams. Limnology and Oceanography, v.51, n.1, p.690-701, 2006. DOI: http://10.4319/lo.2006.51.1 part 2.0690

MATEO-SAGASTA, J.; BURKE, J. Agriculture and water quality interactions: a global overview. SOLAW Background Thematic Report - TR08 FAO. Roma: SOLAW Background Thematic Report, 2010.

METZER, J. P.. O que é ecologia da paisagem? Biota Neutropica, v.1, n.1, p.1-9, 2001.

MILLENNIUM ECOSYSTEM ASSESSMENT. Ecosystems and Human Well-Being: Policy Responses: Findings of the Responses. Whashington: Freshwater Ecosystem Service Island Press, 2005.

MONOD, J.. La technique de culture continue, theorie et applications. Annales de l'Institut Pasteur, n.79, p.390-410, 1950.

MORAES, L. A. F. A.. Visão integrada da ecohidrobiologia para o sustentável dos ecossistemas aquáticos. Oecologia Brasiliensis, v.13 p.676-687, 2009. 
MOSCHINI, L. E.. Diagnóstico e riscos ambientais relacionados a fragmentação de áreas naturais e semi-naturais da paisagem. Estudo de caso: município de Araraquara, SP. Tese (Doutorado) Universidade Federal de São Carlos, São Carlos, 2005.

MOSCHINI-CARLOS, V.; NISHIMURA, P. Y.. A importância e problemática das cianobactérias nos reservatórios eutrofizados. SANEAS, n.40, p.14-17. 2011.

MOURA, M. A. M.; FRANCO, D. A. S.; MATALLO, M. B.. Manejo integrado de macrófitas aquáticas. Biológico, v.71, n.1, p.77-82, 2009.

NASCIMENTO, W. M.; VILLAÇA, M. G.. Bacias hidrográficas: planejamento e gerenciamento. Revista Eletrônica da Associação dos Geógrafos Brasileiros, n.7, p.102-121, 2008.

NOVAES, W.. Os desafios do século XXI. Estudos Avançados, v.14, n.40, p.107-115, 2000. DOI: http://dx.doi.org/10.1590/S0103-40142000000300011

PASCOAL, C.; CÁSSIO, F.. Contribution of Fungi and Bacteria to Leaf Litter Decomposition in a Polluted River. Appl. Environ. Microbiol, v.70, n.9, p. 266-5273, 2004.

PISTORI, R. E. T. et al. Influence of aquaculture effluents on the growth of Salvinia molesta. Acta Limnologica Brasiliensia, v.22, n.2, p.179-186, 2010. DOI: http://dx.doi.org/10.4322/actalb.02202007

POMPÊO, M.. Monitoramento e manejo de macrófitas aquáticas. Oecologia Brasiliensis, v.12, n.3, p.406424, 2008.

POSTEL, S.; CARPENTER, S.. Freshwater Ecosystem Service. Washington: Island Press, 1997.

RAST, W.; HOLLAND, M.; RYDING, S.. Eutrophication management framework for the policy-maker. França: UNESCO, 1989.

RIER, S. T.; STEVENSON, R. J.. Response of periphytic algae to gradients in nitrogen and phosphorus in streamside mesocosms. Hydrobiologia, v.561, n.1, p.131-147, 2006. DOI: http://dx.doi.org/10.1007/s10750$\underline{005-1610-6}$

RIO, G. A. P.; MOURA, V. P.; PEIXOTO, M. N. O.. Gestão de recursos hídricos: dificuldades de articulações territoriais. In: SIMPÓSIO DE RECURSOS HÍDRICOS DO CENTRO-OESTE, 2. Anais. Campo Grande, 2002.

RIPL, W.. Biochemical oxidation of polluted lake sediment with nitrate. A new restoration method. Ambio, v.4, n.3, p.312-315, 1976.

ROCKSTRÖM et al. A safe operating space for humanity. Nature, v.461, 472-475, 2009. DOI: http://dx.doi.org/10.1038/461472a

ROSEMOND, A. D. P. J.; MULHOLLAND, J. W. E.. Top-down and bottom-up control of stream periphyton: effects of nutrients and herbivores. Ecology, v.74, n.1264-1280, 1993.

ROYER, T. D.; MINSHALL, G. W.. Effects of nutrient enrichment and leaf quality on the breakdown of leaves in a hardwater stream. Freshwater Biology, v.46, n.5, p.603-610, 2001. DOI: http://10.1046/j.13652427.2001.00694.x

SABATER, S. et al. Effects of nutrient inputs in a forested Mediterranean stream under moderate light availability. Archiv Fur Hydrobiologie, v.163, n.4, p.479-496, 2005. DOI: http://dx.doi.org/10.1127/00039136/2005/0163-0479

SETTI, A. A. et al. Introdução ao gerenciamento de recursos hídricos. Brasília: Agência Nacional de Energia Elétrica/Agência Nacional das Águas, 2001.

SHAW, G. R.; MOORE, D. P.; GARNETT C.. Eutrophication and algal Bloom. Milwaukee: University of Wisconsin-Milwaukee, 2003.

SIQUEIRA, D. B.; OLIVEIRA-FILHO, E. C.. Cianobactérias de água doce e saúde pública: uma revisão. Ciências da Saúde, v.3, n.1, p.109-127, 2005. 
SONDERGAARD, M.. Nutrient dynamics in lakes: with emphasis on phosphorus, sediment and lake restoration. PHD (Dissertation) - Environmental Research Institute University of Aarhus, Denmark, 2007.

SLANEY, P. A.; WARD, R.. Experimental fertilization of nutrient deficient streams in British Columbia. Québec: connaître les règles du jeu pour réussir, 1993.

SMIL, V.. Phosphorous in the environment: natural flows and human interfaces. Annual Review of Energy and the Environment, v.25, p.53-88, 2000.

SMITH, V. H.; SCHINDLER, D. W.. Eutrophication science: where do we go from here? Trends in Ecology and Evolution, v.24, n.4, p.201-207, 2009.

SMITH, V. H.; TILMAN, G. D.; NEKOLA, J. C.. Eutrophication: impacts of excess nutrient inputs on freshwater, marine, and terrestrial ecosystems. Environmental Pollution, v.100, n.1, p.179-196, 1999. DOI: http://10.1016/S0269-7491(99)00091-3

STEVENSON, R. J.. An introduction to algal ecology in freshwater benthic habitats. San Diego: Academic Press, 1996.

STEVENSON, R. J. et al. Comparing effects of nutrients on algal biomass in streams in two regions with different disturbance regimes and with applications for developing nutrient criteria. Hydrobiologia, v.561, n.1, p.149-165, 2006.

SUBERKROPP, K.; CHAUVET, E.. Regulation of leaf breakdown by fungi in streams: influences of water chemistry. Ecology, v.76, p.1433-1445, 1995. DOI: http://dx.doi.org/10.2307/1938146

THOMAS, S. M.; BINI, L. M.. Ecologia e manejo de macrófitas aquáticas em reservatórios. Acta limnologica Brasiliensia, v.10, n.1, p.103-116, 1998.

TUNDISI, J. G.; TUNDISI-MATSUMURA, T.. Lagos e reservatórios. São Carlos: Instituto Internacional de Ecologia, 2002.

TUNDISI, J. G.. Água no século XXI. Enfrentando a Escassez. São Carlos: RiMa, 2003.

UNITED NATIONS ENVIRONMENTAL PROGRAMME - UNEP. Planning and Management of Lakes and Reservoirs: An Integrated Approach to Eutrophication. Osaka: UNEP, 2001.

WALTON, S. P.; WELCH, E. B.; HORNER, R. R.. Stream periphyton response to grazing and changes in phosphorus concentration. Hydrobiologia, v.302, p.31-46, 1995.

WARREN, C. E. et al. Trout production in an experimental stream enriched with sucrose. The Journal of Widlife Management, v.2228, n.4, p.617-660, 1964. DOI:

http://dx.doi.org/10.2307/3798780?uid=3737664\&uid=2\&uid=4\&sid=21102331314441

WETZEL, R. G.. Limnology: lake and river ecosystems. San Diego: Academic Press., 2001.

WEYERS, H. S.; SUBERKROPP, K.. Fungal and bacterial production during the breakdown of yellow poplar leaves in two streams. J. N. Am. Benthol. Soc., v.15, n.4, p.408-420, 1996.

XAVIER, C. F.; DIAS, L. N.; BRUNKOW, R.. Eutrofização. Curitiba: Sanepar, 2005.

YANG, X.; WU, X.; HAO, H.; HE, Z.. Mechanisms and assessment of water eutrophication. Journal of Zhejiang University Science, v.9, n.3, p.197-209, 2008. 